\title{
Entrevista com Giorgio Agamben
}

\author{
Entrevistadora: Flavia Costa \\ Tradução de Susana Scramim
}

Flavia Costa: Na introdução de Homo Sacer I, você afirma que havia concebido inicialmente o livro como uma resposta à "sangrenta mistificação de uma nova ordem planetária" (e que em seu desenvolvimento se viu diante de problemas, como o da sacralidade da vida, que não estavam no plano inicial). Como se conforma a partir de então seu projeto intelectual?

GIORGIO AGAMBEN: Quando comecei a trabalhar em Homo Sacer, soube que estava abrindo um canteiro que implicaria anos de escavações e de pesquisa, algo que não poderia jamais ser levado a termo e que, em todo caso, não poderia ser esgotado certamente em um só livro. Daí que o algarismo I no frontispício de Homo Sacer é importante. Depois da publicação do livro, freqüentemente me acusam de oferecer ali conclusões pessimistas, quando na realidade deveria ter ficado claro desde o princípio que se tratava somente de um primeiro volume, no qual expunha uma série de premissas e não de conclusões. Talvez tenha chegado o momento de explicitar o plano da obra, ao menos tal como ele se apresenta agora em minha mente. Ao primeiro volume $(O$ poder soberano $e$ a vida nua, publicado em 1995), seguirá um segundo, que terá a forma de uma série de investigações genealógicas sobre os paradigmas (teológicos, jurídicos e biopolíticos) que têm exercido uma influência determinante sobre o desenvolvimento e a ordem política global das sociedades ocidentais. O livro Estado de exceção (publicado em 2003) não é senão a primeira dessas investigações, uma arqueologia do direito que, por evidentes razões de atualidade e de urgência, pareceu-me que devia antecipar em um volume à parte. Porém, inclusive aqui, o algarismo $I I$, indicando a seqüência da série, e o algarismo $I$ no frontispício indicam que se trata unicamente da primeira parte de um livro maior, que compreenderá um tipo de arqueologia da biopolítica sob a forma de diversos estudos sobre a guerra civil, a origem teológica da oikonomia, o juramento e o conceito de vida (zoé) que estavam já nos fundamentos de Homo Sacer I. O terceiro volume, que contém uma teoria do sujeito ético como testemunha, apareceu no ano de 1998 com o título Ciò che resta di Auschwitz. L'Archivio e il testimone. No entanto, talvez será somente com o quarto volume que a investigação completa aparecerá sob sua luz própria. Trata-se de um projeto para o qual não só é extremamente difícil individualizar um âmbito de investigação adequado, senão que tenho a impressão de que a cada passo o terreno desaparece debaixo dos meus pés. Posso dizer unicamente que no centro desse quarto livro estarão os conceitos de formade-vida e de uso, e que o que está posto em jogo ali é a tentativa de capturar a outra face da vida nua, uma possível transformação da biopolítica em uma nova política.

* Tradutora de Estado de excepción. Buenos Aires: Editorial Adriana Hidalgo, 2004. 
F. C.: Você integra um grupo não muito extenso de pesquisadores europeus que têm realizado uma leitura atenta de autores como Martin Heidegger e Carl Schmitt, e a tem incluído no marco de um pensamento - por assim dizer emancipatório. Como foi se articulando em sua bibliografia intelectual a leitura desses autores?

G. A.: Os dois autores que você cita tiveram em minha vida um peso diferente. $\mathrm{O}$ encontro com Heidegger foi relativamente cedo, e ele inclusive foi determinante em minha formação depois dos seminários de Lê Thor, em 1966 e em 1968. Mais ou menos nos mesmos anos durante os quais eu lia Walter Benjamin, leitura que talvez me serviu de antídoto ante o pensamento de Heidegger. Estava em questão o conceito mesmo de filosofia, o modo pelo qual deveria responder à pergunta, prática e teórica ao mesmo tempo: que é a filosofia? $\mathrm{O}$ encontro com Carl Schmitt se deu, por outro lado, relativamente tarde, e teve um caráter totalmente distinto. Era evidente (creio que é evidente para qualquer um que não seja estúpido nem tenha má-fé, ou, como acontece freqüentemente, as duas coisas juntas) que, se queria trabalhar com o direito e sobre a política, era com ele que eu deveria medir-me. Como com um inimigo, antes de tudo - mas a antinomia amigo-inimigo era precisamente uma das teses schmittianas que eu queria pôr em questão.

F. C.: A recepção de sua obra tem sido polêmica em alguns países, sobretudo na Alemanha. Talvez um dos momentos mais provocadores de seu trabalho seja quando rastreia e expõe a matriz comum (a "íntima solidariedade") entre democracia e totalitarismo. Como você comenta isso?

G. A.: Na perspectiva arqueológica, que é a de minha pesquisa, as antinomias (por exemplo, a da democracia versus totalitarismo) não desaparecem, mas perdem seu caráter substancial e se transformam em campos de tensões polares, entre as quais é possível encontrar uma via de saída. Não se trata, então, de distinguir o que é bom do que é mal em Heidegger ou em Schmitt. Deixemos isto aos bem pensantes. O problema, sobretudo, é que se não se compreende o que se põe em jogo no fascismo, não se chega a observar sequer o sentido da democracia.

F. C.: O que você entende por arqueologia? Que lugar ocupa em seu método de trabalho?

G. A.: Meu método é arqueológico e paradigmático num sentido muito próximo ao de Foucault, mas não completamente coincidente com ele. Trata-se, diante das dicotomias que estruturam nossa cultura, de ir além das exceções que as têm produzido, porém não para encontrar um estado cronologicamente originário, mas, ao contrário, para poder compreender a situação na qual nos encontramos. A arqueologia é, nesse sentido, a única via de acesso ao presente. Porém, superar a lógica binária significa, sobretudo, ser capaz de transformar cada vez as dicotomias em bipolaridades, as oposições substanciais num campo de forças percorrido por tensões polares que estão presentes em cada um dos pontos sem que exista alguma possibilidade de traçar linhas claras de demarcação. Lógica do campo contra lógica da substância. Significa, entre outras coisas, que entre A e A se dá um terceiro 
elemento que não pode ser, entretanto, um novo elemento homogêneo e similar aos anteriores: ele não é outra coisa que a neutralização e a transformação dos dois primeiros. Significa, enfim, trabalhar por paradigmas, neutralizando a falsa dicotomia entre universal e particular. Um paradigma (o termo em grego quer dizer simplesmente "exemplo") é um fenômeno particular que, enquanto tal, vale por todos os casos do mesmo gênero e adquire assim a capacidade de construir um conjunto problemático mais vasto. Nesse sentido, o panóptico em Foucault e o duplo corpo do rei em Kantorowicz são paradigmas que abrem um novo horizonte para a investigação histórica, subtraindo-a aos contextos metonímicos cronológicos (França, o século XVIII). No mesmo sentido, em meu trabalho, lancei mão constantemente dos paradigmas: o homo sacer não é somente uma figura obscura do direito romano arcaico, senão também a cifra para compreender a biopolítica contemporânea. O mesmo pode ser dito do "muçulmano" em Auschwitz e do estado de exceção.

F. C.: No livro, você historiciza o processo - acelerado depois da Primeira Guerra Mundial - segundo o qual o estado de exceção se transforma em regra; o paradigma de governo dominante na política contemporânea. Como você chega a esta idéia?

G. A.: Para mim tratava-se, sobretudo, de compreender a profunda transformação que se havia produzido na constituição material, isto é, na vida política das assim chamadas democracias nas quais vivemos. Está claro que nenhuma das categorias fundamentais da tradição democrática manteve seu sentido, sobre isso não podemos estar iludidos. Em Estado de exceção tentei indagar essa transformação de um ponto de vista do direito; perguntei-me o que significa viver em um estado de exceção permanente. Creio que os dois campos de investigação que Foucault deixou de lado, o direito e a teologia, são extremamente importantes para compreender nossa situação presente. Em todo caso, é nesses dois âmbitos que tenho trabalhado nesses últimos anos.

F. C.: Por que você considera fundamental uma teoria geral do estado de exceção: uma teoria do vazio do direito que, contudo, o funda? Imagina uma práxis para essa teoria?

G. A.: Algumas vezes foi dito que em cada livro há algo assim com um centro que permanece escondido; e que é para aproximar-se, para encontrar e - às vezes - para evitar esse centro que se escreve esse livro. Se tivesse de dizer qual é, no caso do Estado de exceção, esse núcleo problemático, diria que está na relação entre anomia e direito, que no curso da pesquisa apareceu como a estrutura constitutiva da ordem jurídica. Um dos objetivos do livro era precisamente a tentativa de abordar e analisar essa dupla natureza do direito, essa ambigüidade constitutiva da ordem jurídica pela qual esta parece estar sempre fora e dentro de si mesma, simultaneamente vida e norma, fato e direito. $O$ estado de exceção é o lugar no qual essa ambigüidade vem à luz e, simultaneamente, o dispositivo que deveria manter unidos os dois elementos contraditórios do sistema jurídico. Ele é, nesse sentido, aquilo que funda o nexo entre violência e direito e, ao mesmo tempo, no ponto em que se torna "efetivo", aquilo que rompe com esse nexo. E para 
responder à segunda parte de sua pergunta, diria que a ruptura do nexo entre violência e direito abre duas perspectivas à imaginação (a imaginação é naturalmente já uma práxis): a primeira é a de uma ação humana sem nenhuma relação com o direito, a violência revolucionária de Benjamin ou um "uso" das coisas e dos corpos que não tenha nunca a forma de um direito; a segunda é a de um direito sem nenhuma relação com a vida - o direito não aplicado, mas somente estudado, do qual Benjamin dizia que é a porta da justiça.

F. C.: Você afirma que não há um retorno possível do estado de exceção em que vivemos imersos para o estado de direito. Que a tarefa que nos ocupa é, em todo caso, a de denunciar a ficção da articulação entre violência e direito, entre vida e norma, para abrir ali a cesura, o campo da política. Contudo, não nos devemos também uma teoria, não tanto do "poder constituinte" como da "instituição política", quer dizer, uma teoria sobre a "práxis articulatória" que inclua a politicidade do vivente como um elemento central?

G. A.: Precisamente porque se trata de romper o nexo entre violência e direito, o problema aqui é que devemos superar a falsa alternativa entre poder constituinte e poder constituído, entre a violência que instala o direito e a violência que o conserva. Porém, precisamente por isso me parece que não se trata tanto de "instituir" e de "articular", como de destruir e desarticular. Em geral, em nossa cultura o homem tem sido pensado sempre com a articulação e a conjunção dos princípios opostos: uma alma e um corpo, a linguagem e a vida, nesse caso um elemento político e um elemento vivente. Devemos, ao contrário, aprender a pensar o homem como aquele que resulta da desconexão desses dois elementos e investigar não o mistério metafísico da conjunção, mas o mistério prático e político da separação.

F. C.: A dinâmica de como desinstalar o instituído sem instituir ao mesmo tempo uma nova instituição remete certamente à idéia de revolução permanente. Pergunto-lhe não pelo "o que fazer?", mas sim até onde crê que é possível e desejável orientar-se na tentativa de pensar uma política "completamente nova"?

G. A.: Diria que o problema da revolução permanente é o de uma potência que não se desenvolve nunca em ato, e, ao contrário, sobrevive a ele e nele. Creio que seria extremamente importante chegar a pensar de um modo novo a relação entre a potência e o ato, o possível e o real. Não é o possível que exige ser realizado, mas é a realidade que exige tornar-se possível. Pensamento, práxis e imaginação (três coisas que jamais deveriam ser separadas) convergem nesse desafio comum: tornar possível a vida.

F. C.: No primeiro capítulo - de $O$ Estado de exceção - você assinala que, em que pese a crescente conversão das democracias parlamentares em governamentais, e o aumento do "decisionismo" do poder executivo, os cidadãos ocidentais não registram essas mudanças e crêem seguir vivendo em democracias. Você tem uma hipótese sobre por que isso acontece? Caberia enfocar esse tema com base em uma teoria sobre a sujeição voluntária ao poder disciplinar (aquilo que Legendre chama "o modo em que o poder se faz amar")? 
G. A.: O problema da sujeição voluntária coincide com aqueles processos de subjetivação sobre os quais trabalhava Foucault. Foucault mostrou, parece-me, que cada subjetivação implica a inserção em uma rede de relações de poder, nesse sentido uma microfísica do poder. Eu penso que tão interessantes como os processos de subjetivação são os processos de dessubjetivação. Se nós aplicamos também aqui a transformação das dicotomias em bipolaridades, poderemos dizer que o sujeito apresenta-se como um campo de forças percorrido por duas tensões que se opõem: uma que vai até a subjetivação e outra que procede em direção oposta. O sujeito não é outra coisa que o resto, a não-consciência desses dois processos. Está claro que serão as considerações estratégicas aquelas que decidirão, a cada momento, sobre qual pólo fazer a alavanca para desativar as relações de poder, de que modo fazer jogar a dessubjetivação contra a subjetivação e viceversa. Letal é, por outro lado, toda política das identidades, ainda que se trate da identidade do contestatário e a do dissidente.

F. C.: Você afirma que "vida nua" e "norma" não são coisas preexistentes à máquina biopolítica, são um produto de sua articulação. Você poderia explicar isto? Porque é mais simples compreender que o direito foi "inventado", mas custa mais se desembaraçar da idéia de que os seres humanos somos, em algum sentido, "existências nuas", que pouco a pouco vamos aprovisionando-nos de nossas roupagens: língua, normas, hábitos...

G. A.: Aquilo que chamo vida nua é uma produção específica do poder e não um dado natural. Enquanto nos movimentarmos no espaço e retrocedermos no tempo, jamais encontraremos - nem sequer as condições mais primitivas - um homem sem linguagem e sem cultura. Nem sequer a criança é vida nua: ao contrário, vive em uma espécie de corte bizantina na qual cada ato está sempre já revestido de suas formas cerimoniais. Podemos, por outro lado, produzir artificialmente condições nas quais algo assim como uma vida nua se separa de seu contexto: o muçulmano em Auschwitz, a pessoa em estado de coma etc. É no sentido que eu dizia antes que é mais interessante indagar como se produz a desarticulação real do humano do que especular sobre como foi produzida uma articulação que, pelo o que sabemos, é um mitologema. O humano e o inumano são somente dois vetores no campo de força do vivente. E esse campo é integralmente histórico, se é verdade que se dá história de tudo aquilo de que se dá vida. Porém, nesse continuum vivente se podem produzir interrupções e cesuras: o "muçulmano" em Auschwitz e o testemunho que responde por ele são duas singularidades desse gênero.

F. C.: Em Homo sacer I você diz: "O corpo técnico do Ocidente já não pode superar-se em outro corpo técnico ou integralmente político [...]. Antes será preciso fazer do próprio corpo biopolítico, da vida nua mesma, o lugar no qual se constitui e assenta uma forma de vida vertida integralmente nessa vida nua. Um bios que seja somente sua zoê". Como você analisa as ilusões de "superar" o corpo biológico (e biopolítico) num corpo técnico?

G. A.: A frase que você citou sobre um bios que é somente sua zoé é para mim o selo e a empresa do que resta pensar. Todos os problemas, incluído o da técnica, deverão ser reinscritos na perspectiva de uma vida inseparável de sua 
forma. No fundo, a vida fisiológica não é outra coisa que uma técnica esquecida, um saber tão antigo que já perdemos toda memória dele. Uma apropriação da técnica não poderá ser feita sem um re-pensamento preliminar do corpo biopolítico do Ocidente.

F. C.: Nos últimos anos, muitas das energias do pensamento sobre a resistência e a emancipação se concentraram em desenvolver uma teoria da defecção, do êxodo (por exemplo, penso em Toni Negri e Michael Hardt, Paolo Virno, Albert Hirschmann). Quer dizer, diante da expansão totalitária em escala global, parece haver uma aposta na negatividade, no silêncio e no exit. Qual a sua opinião sobre isto?

G. A.: Para dizer a verdade, não estou muito convencido de que o êxodo seja hoje um paradigma verdadeiramente praticável. O sentido desse paradigma é, por outro lado, solidário do paradigma do Império, com o qual forma sistema. A analogia com a história da relação entre vida monástica e o Império Romano nos primeiros séculos da era cristã é iluminadora. Também nessa época, fizeram frente a um poder global centralizado formas de êxodo organizado que deram vida às grandes ordens conventuais. A analogia com a situação descrita em um livro recente que teve muita sorte é evidente. Inclusive, às vezes, penso que Negri e Hardt têm perfeito equivalente em Eusebio Cesarea, o teólogo da corte de Constantino (que Overbeck definia ironicamente como o friser da peruca teológica do imperador). Eusebio é o primeiro cristão a teorizar sobre a superioridade do único poder imperial sobre o poder das diversas pessoas e nações. Ao único Deus nos céus corresponde um único império sobre a terra. A história das relações entre Igreja e Império Romano é uma mescla e uma alternância de êxodo e alianças, de rivalidade e negociatas. Contudo, a cidade celeste de Agostinho ainda é peregrina, quer dizer, está no êxodo mesmo quando está em seu próprio terreno. Não creio que tenha sentido aplicar hoje o mesmo modelo. O êxodo da vida monástica fundavase de fato sobre uma radical heterogeneidade da forma de vida cristã e sobre uma sólida fé comum, apesar disso, não alcançou ser verdadeiramente antagonista. Hoje, o problema é que uma forma de vida verdadeiramente heterogênea não existe, ao menos nos países do capitalismo avançado. Nas condições presentes, o êxodo pode assumir somente formas subalternas e não é uma causalidade se termina pedindo ao inimigo imperial que lhe pague um salário. Está claro que uma vida separada de sua forma, uma vida que se deixa subjetivar como vida nua não estará em condições de construir uma alternativa ao império. O que não significa que não seja possível trazer do êxodo modelos e reflexões. Penso, por exemplo, nos conceitos franciscanos de uso e de forma de vida, que são ainda hoje extremamente interessantes. 